\title{
Gastroprotective effect of carob (Ceratonia siliqua L.) against ethanol-induced oxidative stress in rat
}

\author{
Kaïs Rtibi ${ }^{1,2^{*}}$, Mohamed Amine Jabri ${ }^{2,3}$, Slimen Selmi ${ }^{2}$, Abdelaziz Souli ${ }^{1}$, Hichem Sebai ${ }^{2,3}$, Jamel El-Benna ${ }^{4}$, \\ Mohamed Amri ${ }^{1}$ and Lamjed Marzouki ${ }^{2}$
}

\begin{abstract}
Background: We aimed in the present study, at investigating the gastroprotective effect of carob pods aqueous extract (CPAE) against ethanol-induced oxidative stress in rats as well as the mechanism implicated.

Methods: Adult male wistar rats were used and divided into six groups of ten each: control, EtOH $(80 \% \mathrm{v} / \mathrm{v}, 4 \mathrm{~g} / \mathrm{kg}$ b.w.), EtOH $80 \%$ + various doses of CPAE (500, 1000 and $2000 \mathrm{mg} / \mathrm{kg}$, b.w.) and EtOH + Famotidine (10 mg/kg, p.o.) Animals were perorally (p.o.) pre-treated with CPAE during 15 days and intoxicated with a single oral administration of EtOH (4 g/kg b.w.) for two hours.

Results: The colorimetric analysis demonstrated that the CPAE exhibited an importance in vitro antioxidant activity against ABTS and DPPH radicals. We found that CPAE pretreatment in vivo, protected against EtOH-induced macroscopic and histological changes induced in stomach mucosa. Carob extract administration also protected against alcohol-induced volume gastric juice decrease. More importantly, We showed that CPAE counteracted $\mathrm{EtOH}$-induced gastric lipoperoxidation, reversed the decrease of sulfhydryl groups $(-\mathrm{SH})$ an hydrogen peroxide $\left(\mathrm{H}_{2} \mathrm{O}_{2}\right)$ levels, and prevented the depletion of antioxidant enzyme activity of superoxide dismutase (SOD), catalase (CAT) and glutathione peroxidase (GPX).

Conclusions: These findings suggest that CPAE exerted a potential gastro-protective effect against EtOH-induced oxidative stress in rats, due in part, to its antioxidants properties.
\end{abstract}

Keywords: Gastric ulcer, Carob pods, Oxidative stress, Antioxidant capacity, Rat

\section{Background}

In gastrointestinal disorders, ulcer is a common disease with multiple etiologies. This disease, characterized by mucosal damage, is predominantly caused by Helicobacter pylori, antiplatelet agents such as acetylsalicylic acid [1], nonsteroidal anti-inflammatory drugs (NSAIDs) such as oral bisphosphonates, potassium chloride, immunosuppressive medications [2,3], serotonin reuptake inhibitors [4], cigarette smoking and alcohol consumption [5]. The

\footnotetext{
*Correspondence: rtibikais@yahoo.fr

'Laboratoire de Neurophysiologie Fonctionnelle et Pathologies, Département des Sciences Biologiques, Faculté des Sciences de Tunis. Campus Universitaire El Manar II, Tunis 2092, Tunisia

${ }^{2}$ Laboratoire de Physiologie Fonctionnelle et Valorisation des Bio-Resssources, Institut Supérieur de Biotechnologie de Béja, Université de Jendouba,

Avenue Habib Bourguiba, B.P, 382-9000, Béja, Tunisia

Full list of author information is available at the end of the article
}

pathophysiology of gastric ulcer has generally focused on imbalance between aggressive and protective factors in the stomach, such as acid-pepsin secretion, mucosal barrier, mucus secretion, blood flow, cellular regeneration, prostaglandins and epidermal growth factors [6]. Ethanol-induced gastric lesions is mainly related to intense infiltration in the sub-mucosa that promotes formation of reactive oxygen species (ROS), decreased mucus, depletion of sulfhydryl groups and decreased blood flow, resulting in damage of the gastric mucosa [7]. ROS especially hydroxyl radical play the major role in causing oxidative damage of mucosa in all types of ulcers [8]. To determine the possible mechanism by which substances can act to promote gastroprotection, several antioxidants molecules such as quercetin [9] and curcumin [10] were previously investigated. 
Carob (Ceratonia siliqua L.) is a slow-growth ever-green tree cultivated for years in Mediterranean countries. The carob fruit, brown pod 10-25 cm in length, contain many bioactive substances such as sweet carbohydrate, dietary fiber, tannins, and polyphenols [11]. Many of the beneficial health effects associated to consumption of phenolic-rich foods are essentially due to their antioxidant activities [12, 13]. For carob extract, this property has been previously reported in in vivo and in vitro studies $[14,15]$. Recently, we and other discovered that Tunisian leaf carob extract presents some ameliorative effects against alcohol or $\mathrm{CCl}_{4}$-induced oxidative damage in rats tissues $[16,17]$. In addition, carob fiber exhibit high antioxidant capacity determined by the DPPH radical scavenging test, i.e., higher than many other foods rich in polyphenols, such as blueberries, grapes or red wine $[18,19]$.

Accordingly, the present study was designed to evaluate the putative gastroprotective role of the aqueous extract of carob pods (CPAE) (15 days) against oxidative stress induced by acute ethanol exposure and the mechanism involved in such protection.

\section{Methods}

\section{Ethics statement}

The necessary permits for the field studies and collection of carob pods samples were obtained by the Ministry of Agriculture in Tunisia and identified by Mrs. Mouhiba Ben-Naceur, professor of taxonomy in the Higher Institute of Biotechnology of Béja, Tunisia. The Voucher specimens have been deposited with the herbarium of the Higher Institute of Biotechnology of Béja and also in the Department of Biological Sciences, Faculty of Science, Tunisia.

\section{Preparation of carob extract}

The mature carob pods were collected from the region of Tabarka (North-West of Tunisia) during October 2013. Briefly, the plant material was later dried in an incubator at $50{ }^{\circ} \mathrm{C}$ during $72 \mathrm{~h}$ and powdered in an electric blender (Moulinex Ovatio 2, FR). Powder mixture containing carob pulp (90\%) and seeds (10 \%) was dissolved in double distilled water and filtered through a colander (0.5 mm mesh size). Finally, the carob pods aqueous extract was immediately used for in vitro and in vivo experiments.

\section{Free radical-scavenging activities on DPPH}

The antioxidant capacity of the aqueous extract of carob pods was performed using 2,2-diphenyl-1-picrylhydrazyl (DPPH) radical-scavenging activity as previously described by Grzegorczyk et al. [20]. Briefly, various concentrations of CPAE $(20,50,100,150$, and $200 \mu \mathrm{g} / \mathrm{ml})$ were added to $1 \mathrm{ml}$ of $0.1 \mathrm{mM}$ methanol solution of $\mathrm{DPPH}$ and incubated at $27{ }^{\circ} \mathrm{C}$ during $30 \mathrm{~min}$. The optical density of the sample was quantified at $517 \mathrm{~nm}$. DPPH radicalscavenging activity (RSA), expressed as a percentage, was estimated utilizing the following formula:

$$
\operatorname{RSA}(\%)=\frac{A_{\mathrm{DPPH}}{ }^{-}\left(A_{\text {sample }}-A_{\text {control }}\right)}{A_{\mathrm{DPPH}}} \times 100
$$

Ascorbic acid was used as a reference molecule in the same concentration as the test extract.

All the analyses were executed in triplicate. The efficacy concentration $50\left(\mathrm{EC}_{50}\right)$ value was determined as the concentration (in $\mu \mathrm{g} / \mathrm{ml}$ ) of the compound required to scavenge $50 \%$ of the DPPH radical.

\section{Free radical-scavenging activities on ABTS}

The antioxidant capacities of the carob pods aqueous extract were evaluated using the 2,2'-azino-bis [3-ethylbenzthiazoline-6-sulphonic acid] (ABTS) method [21]. Briefly, $1 \mathrm{ml}$ of diluted extract was added to $3 \mathrm{ml}$ of $7 \mathrm{mM}$ ABTS radical solution (ABTS•+) and was kept in dark at room temperature for $60 \mathrm{~min}$. The absorbance was measured at $734 \mathrm{~nm}$. The scavenging capacity was calculated as $((1-\mathrm{Ab} / \mathrm{A} 0) \times 100 \%)$ (Ab and A0 are the absorbance of samples as well as the $\mathrm{ABTS}^{\circ+}$ solution at $734 \mathrm{~nm}$.

\section{Animals and treatment}

Healthy adult male Wistar rats (weighing 220-250 g; housed five per cage) and adult male Swiss Albino mice (weighing approximately 25 g; housed ten per cage) were purchased from Society of Pharmaceutical Industries of Tunisia (SIPHAT, Ben-Arours, TN). Experimental protocols were approved with the guidelines of the Ethical Committee of Science Faculty of Tunis, Tunisia. The test was performed in compliance with the Commission Directive 2000/32/EC and the OECD Guideline 474 [22]. They were provided with standard food (standard pellet diet- Badr Utique-TN) and water ad libitum and maintained in animal house at controlled temperature $\left(22 \pm 2{ }^{\circ} \mathrm{C}\right)$ with a $12 \mathrm{~h}$ light-dark cycle. The rats were divided into half a dozen groups. Group 1 and 2 were served as controls and had bidistilled water $(5 \mathrm{~mL} / \mathrm{kg}$, b.w., p.o.). Groups 3, 4, and 5 were pre-treated with various doses of CPAE (500, 1000 and $2000 \mathrm{mg} / \mathrm{kg}, b . w$. p.o.), while group 6 was pre-treated respectively with famotidine $(10 \mathrm{mg} / \mathrm{kg}$, b.w. p.o.) during 15 days. Rats were fasted for $24 \mathrm{~h}$ before the last administration of CPAE or reference molecules. After $60 \mathrm{~min}$, each animal, except group 1, received $\mathrm{EtOH}(4 \mathrm{~g} / \mathrm{kg}, b . w$.) by oral administration. Two hours later, rats were sacrificed.

\section{Acute toxicity study}

The carob pods aqueous extract in the dose range of 0.05 , $0.1,0.5,1,2,5,10$ and $200 \mathrm{~g} / \mathrm{kg}$ was orally administrated to different groups of mice $(n=10)$. The animals were 
examined every 30 min during $4 \mathrm{~h}$ and then, occasionally for additional period of $8 \mathrm{~h} .24 \mathrm{~h}$ after, the mortality was recorded. The mice were also observed for other signs of toxicity, such as motor co-ordination, righting reflex and respiratory changes.

\section{Evaluation of gastric mucosal damage}

The stomach of each animal was removed and opened along its greater curvature. The tissue was gently rinsed in $\mathrm{NaCl} 0.9 \%$. The lesions in the gastric mucosa were macroscopically examined and the photographs of hemorrhagic erosions were acquired with a Photometrics Quantix digital camera. Ulcer indexes were determined as the sum of the lengths of the whole gastric lesions (in $\mathrm{mm}^{2}$ ) [23]. Two independent, blinded observers performed the measurements of lesion lengths.

\section{Gastric volume juice determination}

Gastric juice was collected and centrifuged at $3000 \mathrm{~g}$ during $5 \mathrm{~min}$ to remove insoluble materials. The supernatant was after measured using graduate tubes [24].

\section{Histopathological analysis}

Immediately after sacrifice, small pieces of stomach were harvested and washed with icecold saline. Tissue fragments were then fixed in a $10 \%$ neutral buffered formalin solution, embedded in paraffin and used for histopathological examination. $5 \mu \mathrm{m}$ thick sections were cut, deparaffinized, hydrated and stained with hematoxylin and eosin (HE). The gastric sections were examined in blind fashion in all treatments [25].

\section{Lipid peroxidation measurement}

Gastric mucosa lipid peroxidation was determined by MDA measurement according to the double heating method [26]. Briefly, aliquots from gastric mucosa homogenates were mixed with BHT-trichloroacetic acid (TCA) solution containing $1 \%$ BHT $(w / v)$ dissolved in $20 \%$ TCA $(w / v)$ and centrifuged at $1000 \times g$ for $5 \mathrm{~min}$ at $4{ }^{\circ} \mathrm{C}$. Supernatant was blended with a solution containing ( $0.5 \mathrm{~N} \mathrm{HCl}, 120 \mathrm{mM}$ TBA buffered in $26 \mathrm{mM}$ Tris) and then heated at $80{ }^{\circ} \mathrm{C}$ for $10 \mathrm{~min}$. After cooling, the absorbance of the resulting chromophore was determined at $532 \mathrm{~nm}$. MDA levels were determined by using an extinction coefficient for MDA-TBA complex of $1.56 \times 10^{5} \mathrm{M}^{-1} \cdot \mathrm{cm}^{-1}$.

\section{Thiol group measurement}

The total concentration of thiol groups $(-\mathrm{SH})$ was performed according to Ellman's method [27]. Briefly, aliquots from gastric mucosa were mixed with $100 \mu \mathrm{l}$ of $10 \%$ SDS and $800 \mu \mathrm{l}$ of $10 \mathrm{mM}$ phosphate buffer (pH 8), and the optical density was measured at $412 \mathrm{~nm}\left(\mathrm{~A}_{0}\right)$. After adding $100 \mu \mathrm{l}$ of 5,5'-dithiobis-(2-nitrobenzoic acid)
(DTNB), the reaction mixture was incubated at $37{ }^{\circ} \mathrm{C}$ during 60 min and a new value $\left(A_{1}\right)$ was determined. The thiol groups concentration was calculated from $A_{1}$ to $A_{0}$ subtraction using a molar extinction coefficient of $13.6 \times 10^{3} \mathrm{M}^{-1} \cdot \mathrm{cm}^{-1}$. The results were expressed as nmol of thiol groups per mg of protein.

\section{$\mathrm{H}_{2} \mathrm{O}_{2}$ determination}

The gastric mucosa $\mathrm{H}_{2} \mathrm{O}_{2}$ level was performed according to Dingeon et al. [28]. Briefly, the hydrogen peroxide reacts with p-hydroxybenzoic acid and 4-aminoantipyrine in the presence of peroxidase leading to the formation of quinoneimine that has a pink color detected at $505 \mathrm{~nm}$.

\section{Antioxidant enzyme activity assays}

The activity of SOD was determined by using modified epinephrine assays [29]. At alkaline $\mathrm{pH}$, superoxide anion $\mathrm{O}_{2}^{-}$causes the autoxidation of epinephrine to adenochrome; while competing with this reaction, SOD decreased the adenochrome formation. One unit of SOD is defined as the amount of the extract that inhibits the rate of adenochrome formation by $50 \%$. Enzyme extract was added in $2 \mathrm{ml}$ reaction mixture containing $10 \mu \mathrm{L}$ of bovine catalase $(0.4 \mathrm{U} / \mu \mathrm{l}), 20 \mu \mathrm{L}$ epinephrine $(5 \mathrm{mg} / \mathrm{ml})$ and $62.5 \mathrm{mM}$ sodium carbonate/bicarbonate buffer $\mathrm{pH} 10.2$. Changes in absorbance were recorded at $480 \mathrm{~nm}$.

The activity of CAT was assessed by measuring the initial rate of $\mathrm{H}_{2} \mathrm{O}_{2}$ disappearance at $240 \mathrm{~nm}$ [30]. The reaction mixture contained $33 \mathrm{mM} \mathrm{H}_{2} \mathrm{O}_{2}$ in $50 \mathrm{mM}$ phosphate buffer $\mathrm{pH} 7.0$ and the activity of CAT was calculated by using the extinction coefficient of $40 \mathrm{mM}^{-1} \mathrm{~cm}^{-1}$ for $\mathrm{H}_{2} \mathrm{O}_{2}$.

The activity of GPx was quantified by the procedure of Flohé and Günzler [31]. Briefly, $1 \mathrm{~mL}$ of reaction mixture containing $0.2 \mathrm{~mL}$ of gastric mucosa supernatant, $0.2 \mathrm{~mL}$ of phosphate buffer $0.1 \mathrm{M} \mathrm{pH} 7.4,0.2 \mathrm{~mL}$ of GSH $(4 \mathrm{mM})$ and $0.4 \mathrm{~mL}$ of $\mathrm{H}_{2} \mathrm{O}_{2}(5 \mathrm{mM})$ was incubated at $37{ }^{\circ} \mathrm{C}$ for $1 \mathrm{~min}$ and the reaction was stopped by the addition of $0.5 \mathrm{~mL}$ TCA $(5 \%$, w/v). After centrifugation at $1500 \mathrm{~g}$ for $5 \mathrm{~min}$, aliquot $(0.2 \mathrm{~mL})$ from supernatant was combined with $0.5 \mathrm{~mL}$ of phosphate buffer $0.1 \mathrm{M} \mathrm{pH} 7.4$ and $0.5 \mathrm{~mL}$ DTNB $(10 \mathrm{mM})$ and absorbance was read at $412 \mathrm{~nm}$. The activity of GPx was expressed as $\mathrm{nmol}$ of GSH consumed/min/mg protein.

\section{Statistical analysis}

The data were analyzed by one-way analysis of variance (ANOVA) and were expressed as means \pm standard error of the mean (S.E.M.). The data are representative of 10 independent experiments. All statistical tests were two-tailed, and a $p$ value of 0.05 or less was considered significant. 


\section{Results}

\section{Acute oral toxicity of CPAE}

In the acute oral toxicity study, neither abnormal behavior nor mortality was detected during the observation period. Thus, the LD50 value was greater than $20 \mathrm{~g} / \mathrm{kg}$ b.w. for the aqueous extract of carob pods.

\section{In vitro DPPH and ABTS radical scavenging activities}

Several concentrations ranging from $0-200 \mu \mathrm{g} / \mathrm{ml}$ of the CPAE were tested for their antioxidant activities in different in vitro models. We have found that the radicalscavenging activity of CPAE against DPPH and ABTS radicals increased significantly in a dose-dependent manner. The $\mathrm{EC}_{50}$ values calculated from the graph demonstrated that the RSA of CPAE $\left(\mathrm{EC}_{50}=228.22 \pm\right.$ $5.27 \mu \mathrm{g} / \mathrm{mL}$ and $184.41 \pm 3.95 \mu \mathrm{g} / \mathrm{mL}$ respectively for $\mathrm{DPPH}$ and ABTS radical-scavenging activity) appeared similar to that of ascorbic acid $\left(\mathrm{EC}_{50}=190.47 \pm 1.2\right.$ and $174.13 \pm 0.9 \mu \mathrm{g} / \mathrm{mL}$ ) as well known reference molecule (Table 1).

\section{Effect of CPAE on EtOH-induced acute macroscopic gastric injury and volume change}

The macroscopic examination of gastric mucosa is shown in Fig. 1. As expected, EtOH administration exhibited injuries, including hemorrhage and hyperemia. CPAE and famotidine treatment showed a dose-dependent decrease in all macroscopic toxic signs compared with the EtOH treated group. Moreover, quantitative analysis showed that carob extract or reference molecule pre-treatment significantly and dose-dependently reduced the ulcer index, protected against the gastric volume juice decrease, and ameliorated the protection percentage of injury induced by EtOH administration (Table 2).

Effect of CPAE on EtOH-induced gastric microscopic injury We also examined the effect of EtOH and CPAE on gastric mucosa histology and the results are shown in Fig. 2. EtOH 80 \% induced a marked erosive lesion in the gastric tissue. CPAE or famotidine pre-treatment greatly reduced the histopathological changes induced by acute alcohol intoxication.

Table $1 \mathrm{EC}_{50}$ values of DPPH and ABTS radical-scavenging activity carob pods aqueous extract (CPAE). $\mathrm{EC}_{50}$ : the effective concentration of sample that can decrease DPPH or ABTS concentration by $50 \%$

\begin{tabular}{lll}
\hline & $\begin{array}{l}E C_{50} \text { of } D P P H \\
\text { radical-scavenging } \\
\text { activity }(\mu \mathrm{g} / \mathrm{ml})\end{array}$ & $\begin{array}{l}\mathrm{EC}_{50} \text { of } \mathrm{ABTS} \\
\text { radical-scavenging } \\
\text { activity }(\mu \mathrm{g} / \mathrm{ml})\end{array}$ \\
\hline CPAE & $228.22 \pm 5.27$ & $184.41 \pm 3.95$ \\
Ascorbic acid & $190.47 \pm 1.2$ & $174.13 \pm 0.9$ \\
\hline
\end{tabular}

Effect of CPAE on EtOH-induced gastric lipoperoxidation and hydrogen peroxide increase

Bearing on the effect of EtOH and CPAE on oxidative stress condition, we firstly studied the gastric lipoperoxidation and hydrogen peroxide content (Fig. 3a). EtOH intoxication drastically increased the gastric MDA and $\mathrm{H}_{2} \mathrm{O}_{2}$ levels (Fig. 3b). CPAE pre-treatment significantly and dosedependently reversed lipoperoxidation and hydrogen peroxide increase induced by $\mathrm{EtOH}$ intoxication.

\section{Effect of of CPAE on EtOH-induced gastric -SH groups decrease}

We also showed that thiol groups level was significantly reduced in the gastric mucosa of alcohol-treated rats. However CPAE (500, 1000 and $2000 \mathrm{mg} / \mathrm{kg}$, b.w. p.o.) or famotidine (10 $\mathrm{mg} / \mathrm{kg}$, b.w. p.o.) pre-treatment significantly protected against this decrease as compared to EtOH group (Fig. 4).

\section{Effect of CPAE on EtOH-induced antioxidant enzyme activities depletion}

We further looked at the effect of $\mathrm{EtOH}$ and CPAE on antioxidant enzymes activities in gastric mucosa (Fig. 5). EtOH 80 \% significantly increased stomach mucosa antioxidant enzyme activities as SOD (A) and CAT (B) but it significantly decreased the GPx activity $(\mathrm{C})$. However, subacute pre-treatment with carob extract or famotidine significantly reduced the $\mathrm{EtOH}$-induced increase and a decrease in antioxidant enzyme activities to near control levels with the highest dose.

\section{Discussion}

The stomach is a sensitive digestive organ mainly exposed to exogenous pathogens from the diet. In response to these pathogens, the stomach tissue produces ROS such as hydroxyl radical a superoxide anion, which might be related to the development of gastric organic disorders like gastritis, gastric ulcers, and gastric cancer, as well as functional disorders such as functional dyspepsia [32]. Ethanol is considered one of the agents that induce gastric ulcers. The effects of ethanol on gastric mucosa are complicated and multifaceted that may be associated with a disturbance in the balance between gastric mucosal protective and aggressive factors [33]. Ethanol causes injures in the vascular endothelial cells of the gastric mucosa and induces microcirculatory disturbance and hypoxia, linking to the overproduction of oxygen radicals [34]. ROS are produced within the gastrointestinal tract, but their roles in pathophysiology and disease pathogenesis have not been well studied.

Many medicinal plants show in their chemical constitution, flavonoids, triterpenoids and tannins, which protect the stomach mucosa through the induction of gastroprotective mechanisms or acting as natural 

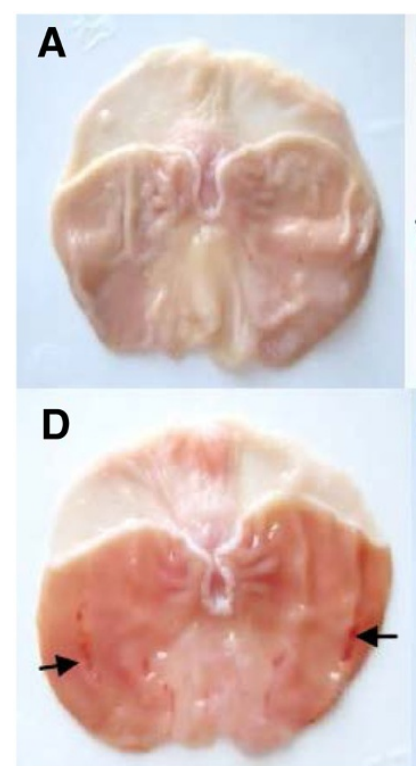

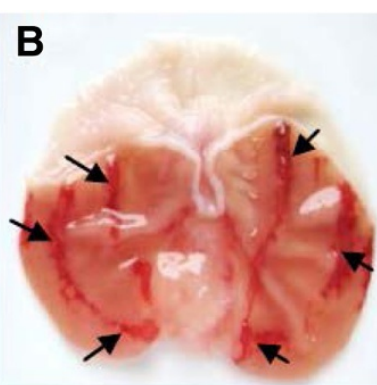

E

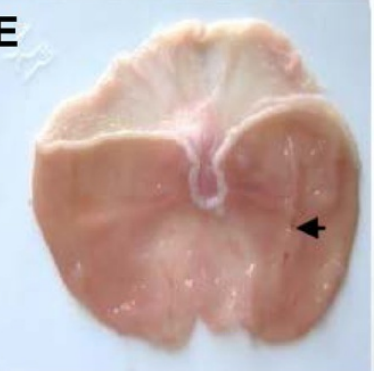

C

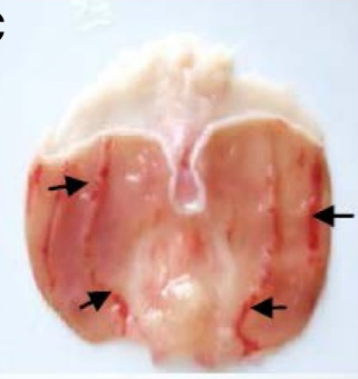

$\mathbf{F}$

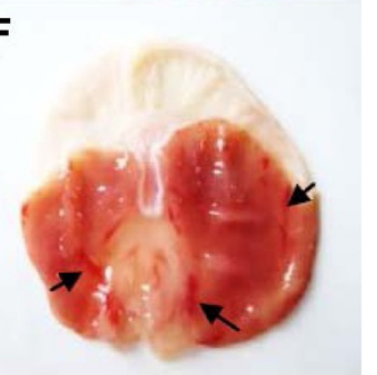

Fig. 1 Subacute effect of caob pods aqueous extract (CPAE) and famotidine (FAM) on macroscopic changes induced by ethanol (EtOH) in rats. Animals were pre-treated with various doses of CPAE (500, 1000 and 2000 mg/kg, b.w., p.o.), FAM (10 mg/kg, b.w., p.o.) or bi-distilled water, challenged with a single oral administration of $\mathrm{EtOH}(4 \mathrm{~g} / \mathrm{kg}$, b.w., p.o.) or $\mathrm{NaCl} 9 \%$ for two hours. a: control; b: EtOH; c: EtOH+ CPAE-500; d: $\mathrm{EtOH}+\mathrm{CPAE}-1000$; e: $\mathrm{EtOH}+\mathrm{CPAE}-2000$ and $\mathbf{f}: \mathrm{EtOH}+\mathrm{FAM})$

antioxidants [35-37]. Flavonoids and tannins are the major group of phenolic compounds that act as primary antioxidants or free radical scavengers [38].

Our phytochemical study, firstly, revealed that its richness total polyphenols, total flavonoids, and condensed tannins [14]. On the other hand, using the DPPH and ABTS radical-scavenging assay, we found that CPAE presents a high scavenging capacity, albeit lesser than ascorbic acid which was used as a reference molecule. The antioxidant capacity of carob is mainly related to

Table 2 Subacute effect of carob pods aqueous extract (CPAE), famotidine (FAM) and ascorbic acid (AA) on macroscopic quantitative changes induced by $\mathrm{EtOH}$ in rats: ulcer mucus volume, ulcer area and percentage protection. Animals were pre-treated with various doses of CPAE $(500,1000$ and $2000 \mathrm{mg} / \mathrm{kg}$, b.w., p.o.), FAM (10 mg/kg, b.w., p.o.) or bi-distilled water, challenged with a single oral administration of $\mathrm{EtOH}$ (4 g/kg, b.w., p.o.) or $\mathrm{NaCl}$ 9\%o for two hours

\begin{tabular}{llll}
\hline Group & $\begin{array}{l}\text { Mucus volume } \\
(\mathrm{ml})\end{array}$ & $\begin{array}{l}\text { Ulcer index } \\
\left(\mathrm{mm}^{2}\right)\end{array}$ & $\begin{array}{l}\text { Protection } \\
\text { percentage (\%) }\end{array}$ \\
\hline Control & $4.3 \pm 0.20$ & -- & -- \\
$\mathrm{EtOH}$ & $1.9 \pm 0.3^{*}$ & $86.2 \pm 2.6^{*}$ & 00 \\
$\mathrm{EtOH}+$ CPAE-500 & $2.9 \pm 0$ & $67.0 \pm 3.6^{\#}$ & 23.4 \\
$\mathrm{EtOH}+$ CPAE-1000 & $3.4 \pm 0.2^{\#}$ & $16.6 \pm 1.4^{\#}$ & 79.8 \\
$\mathrm{EtOH}+$ CPAE-2000 & $3.9 \pm 0.3^{\#}$ & $06.4 \pm 0.9^{\#}$ & 92.2 \\
EtOH + FAM & $3.8 \pm 0.2^{\#}$ & $26.2 \pm 3.3^{\#}$ & 68.1 \\
\hline
\end{tabular}

*: $p<0.05$ compared to control group and \#: $p<0.05$ compared to EtOH group the higher level of phenolic compouds in this fraction [14]. However, these molecules are the major source of their capacity of scavenging free radicals such as superoxide anion $\left(\mathrm{O}_{2}{ }^{\prime}\right)$ and hydroxyl radical $(\mathrm{OH})$ [39].

In vivo, we firstly showed that alcohol administration provoked a clear macroscopic injuries, including hemorrhage and hyperemia as well as histopatological changes such as erosive lesions. CPAE pre-treatment significantly reversed EtOH-induced gastric mucosa macro- and microscopic lesions in a dose-dependent manner. However, gastric mucosa was previously shown to play a critical role in the protection of gastric barriers [40]. It is the first line of defense against acid and adheres together with bicarbonate secreted by the epithelium to serve as a barrier against selfdigestion [41]. In addition, Gastric mucosa is an important protective factor for the gastric mucosa and is capable of acting as an antioxidant agent and reducing mucosal damage mediated by ROS [42]. Tannins could prevent ulcer development either via vasoconstricting effects, or due to their proteins-precipitating where it promotes precipitation of microproteins in the ulceration site, forming an impervious layer over the lining that hinders gut secretions and protects the underlying mucosa from irritants [43]. Moreover, flavonoids have anti-ulcer and gastroprotective properties [44]. However, EtOH-induced gastric ulceration has been previously shown to be attenuated by many plants extracts Aqeratum conyzoides [45], Bacopa monniera and Azadirachta indica [46], Hippocratea excels [47] and Azadirachta indica [48]. However, as far as we know, our report is the first one to deal with fruit extract of Ceratonia 


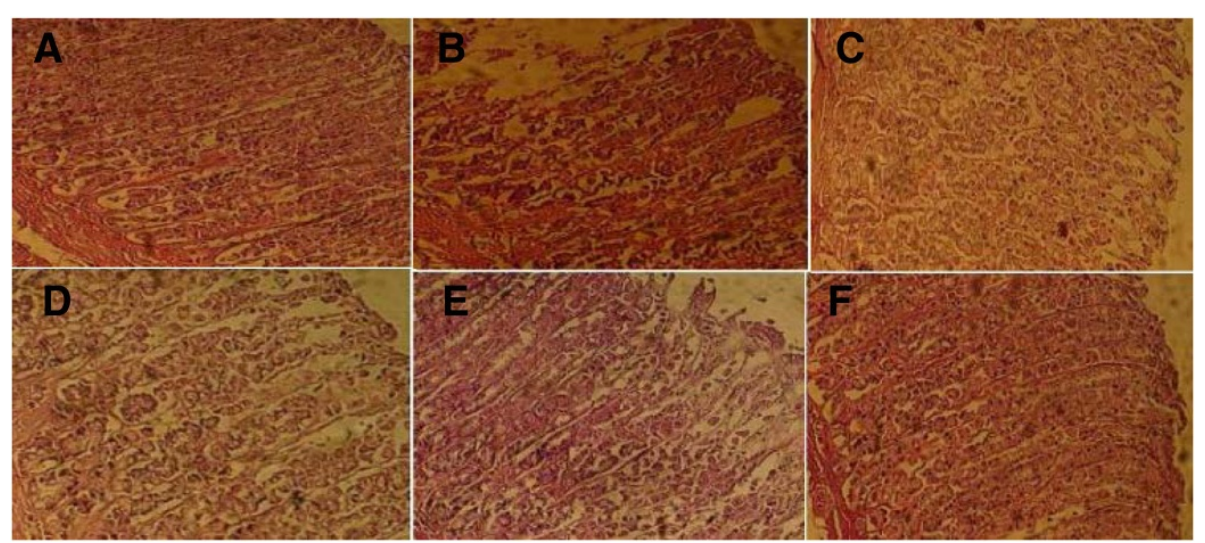

Fig. 2 Subacute effect of caob pods aqueous extract (CPAE) and famotidine (FAM) on histological changes induced by ethanol (EtOH) in rats. Animals were pre-treated with various doses of CPAE (500, 1000 and $2000 \mathrm{mg} / \mathrm{kg}$, b.w., p.o.), FAM (10 mg/kg, b.w., p.o.) or bi-distilled water, challenged with a single oral administration of EtOH (4 g/kg, b.w., p.o.) or NaCl 9\%o for two hours. a: control; b: EtOH; c: EtOH+ CPAE-500; d: $\mathrm{EtOH}+$ CPAE-1000; $\mathbf{e}: \mathrm{EtOH}+$ CPAE-2000 and f: EtOH+ FAM)

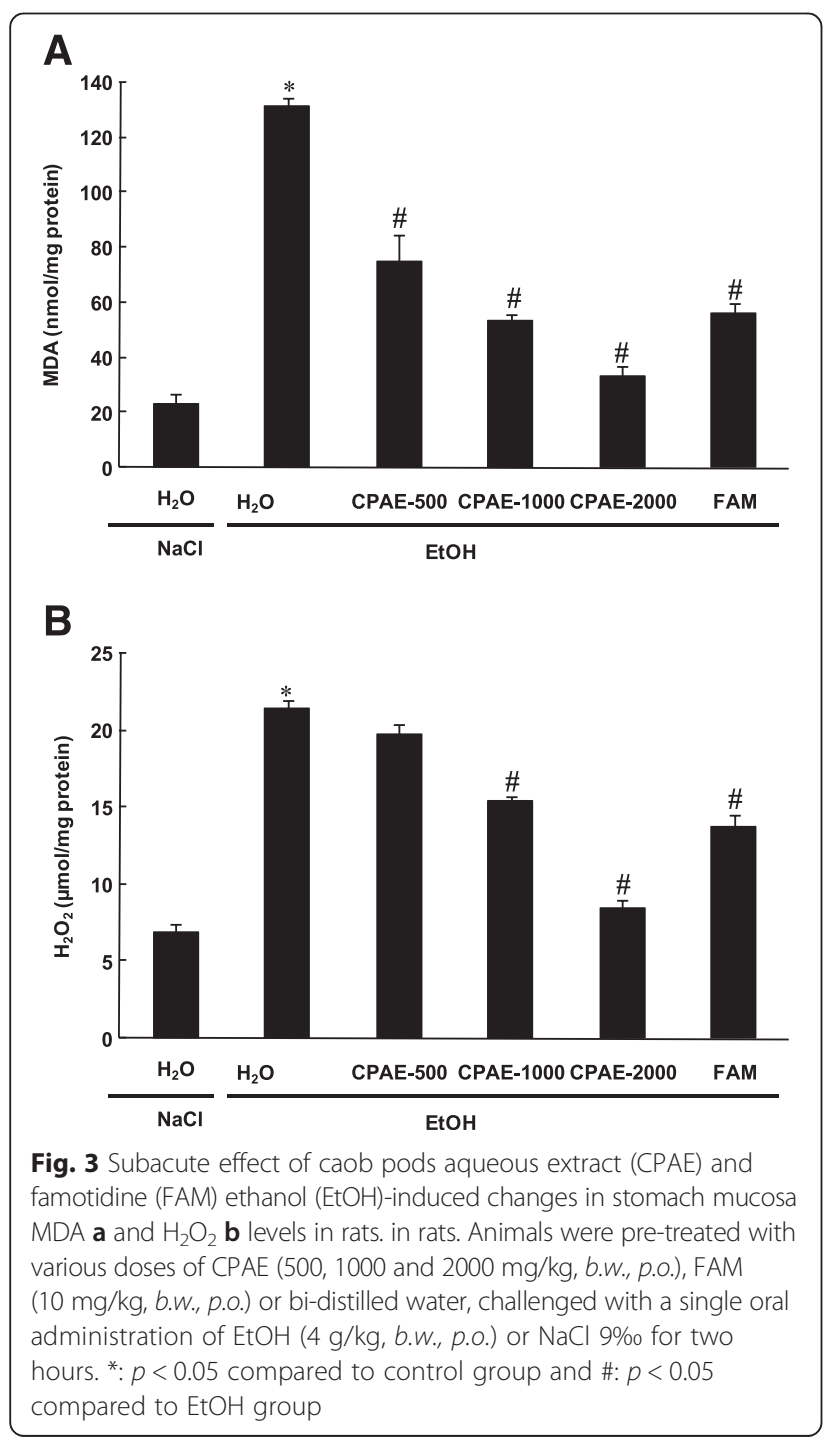

siliqua (carob) protective effect on acute EtOH-induced ulceration in rat gastric mucosa.

We also showed in the present study that $\mathrm{EtOH}$ intoxication induced lipid peroxidation, decrease of thiol groups level, increase of hydrogen peroxide content as well as depletion antioxidant enzyme activities such as SOD, CAT and GPx. Acute alcohol-induced oxidative stress was widely documented in gastric mucosa [49], liver [50], kidney [51], heart [52] and brain [53]. Ethanol administration provoked oxidative imbalance through a number of pathways including the generation of reactive oxygen species [54]. Lipid peroxidation level is an indicator of the generation of ROS in the tissue. However, SOD converts the reactive superoxide radical to $\mathrm{H}_{2} \mathrm{O}_{2}$,

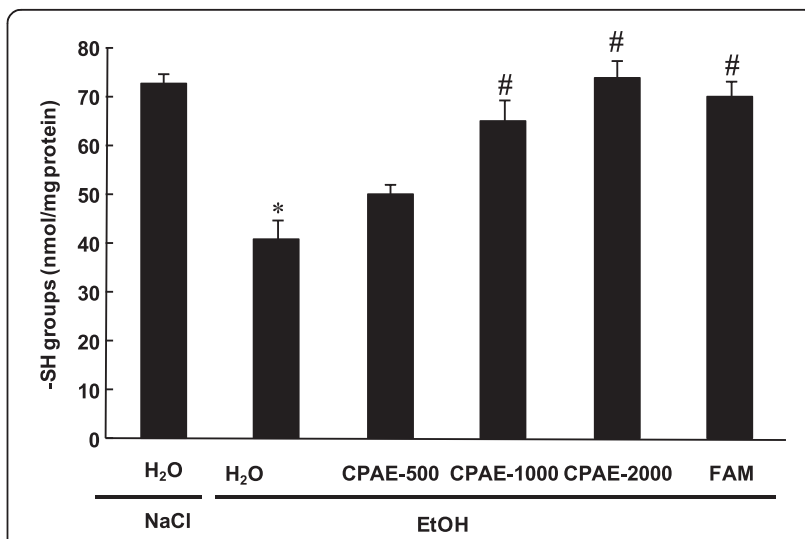

Fig. 4 Subacute effect of caob pods aqueous extract (CPAE) and famotidine (FAM) ethanol (EtOH)-induced changes in stomach mucosa $\mathrm{SH}$ - groups level in rats. in rats. Animals were pre-treated with various doses of CPAE (500, 1000 and $2000 \mathrm{mg} / \mathrm{kg}$, b.w., p.o.), FAM (10 mg/kg, b.w., p.o.) or bi-distilled water, challenged with a single oral administration of EtOH (4 g/kg, b.w., p.o.) or $\mathrm{NaCl} 9 \%$ for two hours. *: $p<0.05$ compared to control group and \#: $p<0.05$ compared to EtOH group 


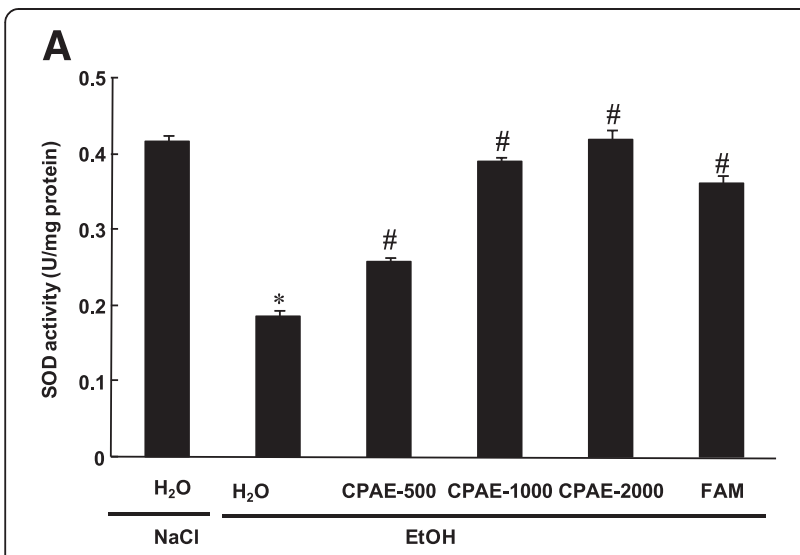

B

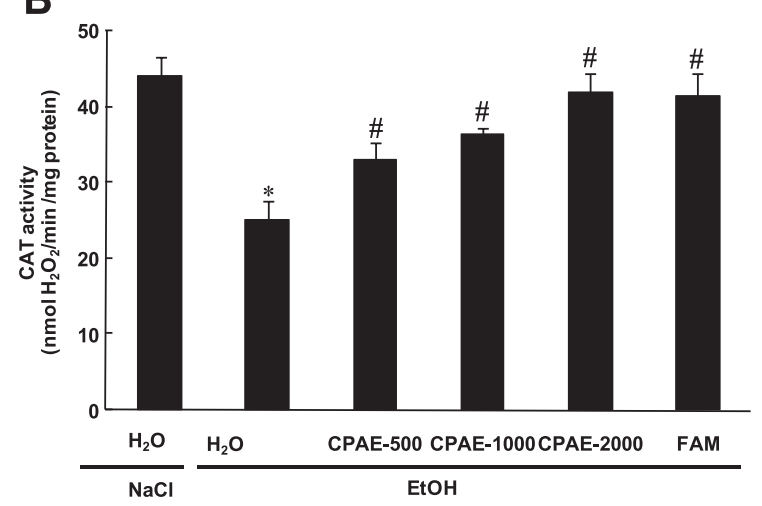

C

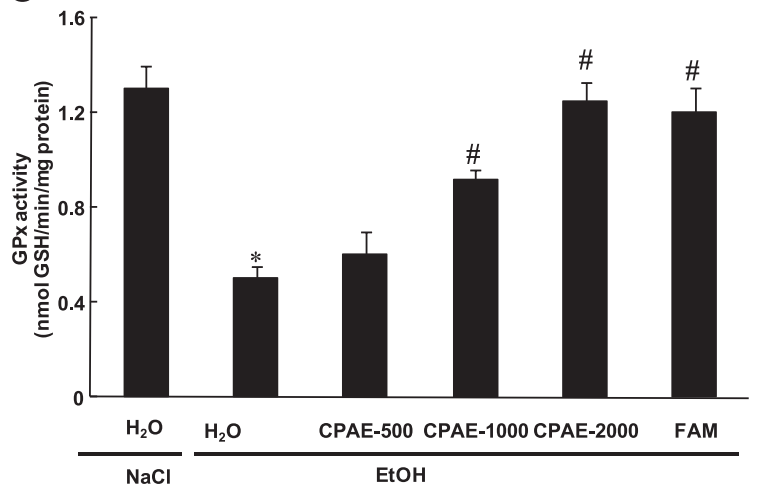

Fig. 5 Subacute effect of caob pods aqueous extract (CPAE) and famotidine (FAM) ethanol (EtOH)-induced changes in stomach mucosa antioxidant enzyme activities : SOD $\mathbf{a}$, CAT $\mathbf{b}$ and GPX $\mathbf{c}$ in rats.. in rats. Animals were pre-treated with various doses of CPAE (500, 1000 and 2000 mg/kg, b.w., p.o.), FAM (10 mg/kg, b.w., p.o.) or bi-distilled water, challenged with a single oral administration of $\mathrm{EtOH}(4 \mathrm{~g} / \mathrm{kg}$, b.w., p.o.) or $\mathrm{NaCl} 9 \%$ for two hours. *: $p<0.05$ compared to control group and \#: $p<0.05$ compared to EtOH group

which was increased in the gastric mucosa and if not scavenged by CAT, it can by itself cause lipid peroxidation by generation of hydroxyl radical [55].

More importantly, we showed that carob extract pretreatment abolished acute EtOH-induced oxidative stress in the gastric mucosa. These data fully corroborated all previously reported in vivo [17] and in vitro [15] antioxidant and anti-inflammatory properties of carob. We also demonstrated in our previous report of Sebai et al. [14] that the aqueous extract of carob pods contains a good amount of total polyphenols, total flavonoïds and condensed tannins. These molecules are the primal source of the antioxidant ability of this plant, by scavenging free radicals as hydroxyl radical $\left(\mathrm{OH}_{\bullet}\right)$ which is the major cause of lipid peroxidation [56]. In addition, it is well known that sulfhydryls are in part involved in gastric cytoprotection [57] and also in the maintain of mucosal barrier integrity and scavenge free radicals formed due to the action of noxious agents [58].

\section{Conclusion}

In conclusion, our data clearly demonstrate that CPAE exerts protective effects against acute ethanol-induced ulceration in the rat gastric mucosa, in part thanks to its antioxidant properties.

\section{Abbreviations}

CPAE: Carob pods aqueous extract; Carob 500 : Carob 500 mg/kg;

Carob 1000 : Carob 1000 mg/kg; Carob 2000 : Carob 2000 mg/kg; CAT: Catalase; GPx: Glutathione peroxidase; $\mathrm{H}_{2} \mathrm{O}_{2}$ : Hydrogenperoxide; MDA: Malondialdehyde; Prot: Proeins; SHs: Sulfhydryl groups; SOD: Superoxide dismutase.

\section{Competing interests}

The authors declare that they have no competing interests.

\section{Authors' contributions}

$\mathrm{KR}, \mathrm{MAJ}, \mathrm{SS}$ and HS designed and performed the study, wrote the manuscript. AS, HS, JE, MA, and MLM performed the study. All authors read and approved the final manuscript.

\section{Acknowledgments}

Financial support of the Tunisian Ministry of "Enseignement Supérieur et Recherche Scientifique" is appreciatively acknowledged.

\section{Author details}

${ }^{1}$ Laboratoire de Neurophysiologie Fonctionnelle et Pathologies, Département des Sciences Biologiques, Faculté des Sciences de Tunis. Campus

Universitaire El Manar II, Tunis 2092, Tunisia. ${ }^{2}$ Laboratoire de Physiologie Fonctionnelle et Valorisation des Bio-Resssources, Institut Supérieur de Biotechnologie de Béja, Université de Jendouba, Avenue Habib Bourguiba, B.P, 382-9000, Béja, Tunisia. 'Laboratoire de Physiologie Intégrée, Faculté des Sciences de Bizerte, 7021 Zarzouna, Bizerte, Tunisia. ${ }^{4}$ INSERM, U1149, Centre de Recherche Sur I'Inflammation, Faculté de Médecine X. Bichat, 75018 Paris, France.

Received: 7 February 2015 Accepted: 11 August 2015 Published online: 20 August 2015

\section{References}

1. Yeomans ND, Hawkey CJ, Brailsford W, Næsdal J. Gastro-duodenal toxicity of low-dose acetylsalicylic acid: a comparison with non-steroidal antiinflammatory drugs. Curr Med Res Opin. 2009;25:2785-93.

2. Yuan YH, Padol IT, Hunt RH. Peptic ulcer disease today. Nat Clin Pract Gastroenterol Hepatol. 2006:3:80-9.

3. Yuan Y, Hunt RH. "Chapter twenty-treatment of non NSAID and non H. pylori gastroduodenal ulcer and hypersecretory states". In: Wolfe MM, Gary LD, Francis AF, Ralph AG, Juan RM, Steer ML, editors. Therapy of Digestive Disorders. Edinburgh, UK: W.B. Saunders; 2006. p. 315-36.

4. Itatsu T, Nagahara A, Hojoetal M. Use of selective serotonin reuptake inhibitors and upper gastrointestinal disease. Int Med. 2011;50:713-7. 
5. Ko JK, Cho $\mathrm{CH}$. Alcohol drinking and cigarette smoking: a "partner" for gastric ulceration. Zhonghua Yi Xue Za Zhi (Taipei). 2000;63(12):845-54.

6. Lima ZP, Severi JA, Pellizzon CH, Brito ARMS, Solis PN, Caceres A, et al. Can the aqueous decoction of mango flowers be used as antiulcer agent? J Ethnopharmacol. 2006;106:29-37.

7. Rao CV, Ojha SK, Radhakrishnan K, Govindarajen R, Rastogi S, Mehrotra SPP. Antiulcer activity of Utleriasalicifolia rhizome extract. J Ethnopharmacol. 2004;91:243-9.

8. Das D, Bandyopadhyay D, Bhattacharjee M, Banerjee RK. Hydroxyl radical is the major causative factor in stress-induced gastric ulceration. Free Radic Biol Med. 1997;23:8-18.

9. Suzuki Y, Ishihara M, Segami T, Ito M. Anti-ulcer effects of antioxidants, quercetin, alpha-tocopherol, nifedipine and tetracycline in rats. Jpn J Pharmacol. 1998;78:435-41.

10. Tuorkey M, Karolin K. Anti-ulcer activity of curcumin on experimental gastric ulcer in rats and its effect on oxidative stress/antioxidant, IL-6 and enzyme activities. Biol Environ Sci. 2009;22:488-95.

11. Papagiannopoulos M, Wollseifen HR, Mellenthin A, Haber B, Galensa R. Identification and quantification of polyphenols in carob fruits (Ceratonia siliqua L.) and derived products by HPLC-UV-ESI/MS. J. Agric. Food. Chem. 2004;52:3784-379.

12. Vinson AJ, Hao Y, Su X, Zubik L. Phenol antioxidant quantity and quality in foods: vegetables. J Agric Food Chem. 1993;46:3630-4.

13. Sawa T, Nakao M, Akaike T, Ono K, Maeda H. Alkylperoxyl radical-scavenging activity of various flavonoids and other phenolic compounds: implications for the anti-tumor - promoter effect of vegetables. J Agric Food Chem. 1999;47:397-402.

14. Hichem S, Abdelaziz S, Latifa C, Kais R, Mohamed A, Jamel EB, et al. In vitro and in vivo antioxidant properties of Tunisian carob (Ceratonia siliqua L.) J Med Food Res. 2013;7:85-90.

15. Kumazawa S, Taniguchi M, Suzuki Y, Shimura M, Kwon MS, Nakayama T. Antioxidant activity of polyphenols in carob pods. J Agric Food Chem. 2002:50:373-7

16. Hsouna AB, Trigui M, Mansour RB, Jarraya RM, Damak M, Jaoua S. Chemical composition, cytotoxicity effect and antimicrobial activity of Ceratonia siliqua essential oil with preservative effects against Listeria inoculated in minced beef meat. Int J Food Microbiol. 2011;148:66-72.

17. Souli A, Sebai H, Chehimi L, Rtibi K, Tounsi H, Boubaker S, Sakly M, El-Benna J, Amri M: Hepatoprotective effect of carob against acute ethanol-induced oxidative stress in rat. Toxicol. Ind. health 2013. doi:10.1177/0748233713475506

18. Haber B. Carob fibre benefits and applications. Cereal Foods World. 2002:47:365-9.

19. Durazzo A, Turfani V, Narducci V, Azzini E, Maiani G, Carcea M. Nutritional characterisation and bioactive components of commercial carobs flours. Food Chem. 2014;15:109-13.

20. Grzegorczyk I, Matkowski A, Wysokinska H. Antioxidant activity of extracts from in vitro cultures of salvia officinalis. Food Chem. 2007;104:636-541.

21. Siddhuraju P. The antioxidant activity and free radical-scavenging capacity of phenolics of raw and dry heated moth bean (Vigna aconitifolia) (Jacq.) Marechal seed extracts. Food Chem. 2006:99:149-57.

22. Organisation for Economic Co-operation and Development (OECD) Test no. 474. mammalian erythrocyte micronucleus test. In: Guideline for the Testing of Chemicals. Paris: OECD Publishing; 1997.

23. Hollander D, Taranawski A, Krause WJ, Gergely H. Protective effect of sucralfate against alcohol-induced gastric mucosal injury in the rat. Gastroenterol. 1985:88:366-74.

24. Maity S, Vedasiromoni JR, Ganguly DK. Antiulcer effect of hot water extract of black tea (Camellia sinensis). J Ethnopharmacol. 1986;46:167-74.

25. Behmer OA, Tolosa EMC, Freitas Neto AG. Manual de técnicas para histologia normal epatológica. EDART-Editora da Universidade de São Paulo 1976,241.

26. Draper HH, Hadley M. Malondialdehyde determination as index of lipid peroxidation. Methods Enzymol. 1990;186:421-31.

27. Ellman GE. Tissue sulfhydryl groups. Arch Biochem Bio-phys. 1959;82:70-7.

28. Dingeon B, Ferry JP, Roullet A. Auto analysis of blood sugar by Trinder's method. Ann Biol Clin. 1975;33:3-13.

29. Kakkar P, Das B, Viswanathan PN. Modified spectrophotometric assay of SOD. Indian J Biochem Biophys. 1984;2:130-2.

30. Aebi H. Catalase. In: Bergmeyer HU, editor. Methods in Enzymatic Analysis. New York: Academic Press Inc; 1974. p. 673-86.

31. Flohé L, Günzler WA. Assays of glutathione peroxidase. Methods Enzymol. 1984;105:114-21.
32. Hidekazu S, Toshihiro N, Hitoshi T, Sachiko M, Toshifumi H. Roles of oxidative stress in stomach disorders. J Clin Biochem Nutr. 2012;50:35-9.

33. Soojin P, Ki-baik H, Tae-young OH, Joo-hyun Jin BS, Ryowon C. Preventive Effect of the Flavonoid, Wogonin, Against Ethanol-Induced Gastric Mucosal Damage in Rats. Digest Dis Sci. 2004;49:384-94.

34. Park JH, Jang KJ, Kim CH, Kim JH, Kim YK, Yoon HM. Ganoderma Lucidum Pharmacopuncture for Teating Ethanol-induced Chronic Gastric Ulcers in Rats. J Pharmacopuncture. 2015;18:72-8.

35. Gonzalez FG, Portela TY, Stipp EJ, Di Stasi LC. Antiulcerogenic and analgesic effects of Maytenus aquifolium, Sorocea bomplandii and Zolernia ilicifolia. J Ethnopharmacol. 2001;77:41-7.

36. Repetto MG, Llesuy SF. Anti-oxidant properties of natural compounds used in popular medicine for gastric ulcers. Brazil J Med Biol Res. 2002;35:523-34.

37. Kahraman A, Erkasap N, Koken T, Serteeser M, Aktepe F, Erkasap S. The antioxidative and antihistaminic properties of quercetin in ethanol induced gastric lesions. Toxicol. 2003;183:133-42.

38. Polterai $\mathrm{O}$. Antioxidants and free-radical scavengers of Natural Origin. Current Org Chem. 1997;1:415-40.

39. Rodrigo R, Bosco C. Oxidative stress and protective effects of polyphenols: comparative studies in human and rodent kidney. A review. Comp. Biochem. Physiol. C. Toxicol. Pharmacol. 2006:142:317-27.

40. Kanuitz JD. Barrier function of gastric mucus. Keio J Med. 1999;48:3-8.

41. Allen A, Flemströn G. Gastroduodenal mucus bicarbonate barrier: protection against acid and pepsin. American J Physiol Cell Physiol. 2005;288:1-19.

42. de Thiago MM, Clenilson MR, Hélio K, Tais MB, Wagner V, Cláudia HP, et al. Hancornia speciosa: Indications of gastroprotective, healing and antiHelicobacter pylori actions. J Ethnopharmacol. 2008;120:161-8.

43. Al-Rehaily AJ, Al-Howiriny TA, Al-Sohaibani MO, Rafatullah S. Gastroprotective effects of 'Amla' Emblica officinalis on in vivo test models in rats. Phytomed. 2002;9:515-22.

44. Zayachkivska OS, Konturek SJ, Drozdowicz D, Konturek PC, Brzozowski T, Ghegotsky MR. Gastroprotective effects of flavonoids in plant extracts. J Physiol Pharmacol. 2005:56:219-31.

45. Shirwaikar A, Bhilegaonkar PM, Malini S, Kumar JS. The gastroprotective activity of the ethanol extract of Ageratum conyzoides. J Ethnopharmacol. 2003;86:117-21.

46. Dorababu M, Prabha T, Priyambada S, Agrawal VK, Aryya NC, Goel RK Effect of Bacopa monniera and Azadirachta indica on gastric ulceration and healing in experimental NIDDM rats. Indian J Exp Biol. 2004;42:389-97.

47. Navarreta A, Trejo-Miranda JL, Reyaes-Trjo L. Principles of root bark of Hipporatea excelasa with gastroprotective activity. J Ethnopharmacol. 2002;79:389-97.

48. Raji Y, Ogunwande IA, Osadebe CA, John G. Effects of Azadirachta indica extract on gastric ulceration and acid secretion in rats. J Ethnopharmacol. 2004;90:167-70.

49. Pan JS, He SZ, Xu HZ, Zhan XJ, Yang XN, Xiao HM, et al. Oxidative stress disturbs energy metabolism of mitochondria in ethanol-induced gastric mucosa injury. World J Gastroenterol. 2008;14:5857-67.

50. Zhao M, Du YQ, Yuan L, Wang NN. Protective effect of puerarin on acute alcoholic liver injury. Am J Chin Med. 2010;38:241-9.

51. Calivarathan L, Laura EN, Thomas MM. Chronic ethanol ingestion induces oxidative kidney injury through taurine-inhibitable inflammation. Free Radical Bio Med. 2014:69:403-16.

52. Kannan M, Wang L, Kang YJ. Myocardial oxidative stress and toxicity induced by acute ethanol exposure in mice. Exp Biol Med (Maywood). 2004;229:553-9.

53. Haorah J, Knipe B, Leibhart J, Ghorpade A, Persidsky Y. Alcohol-induced oxidative stress in brain endothelial cells causes blood-brain barrier dysfunction. J Leukoc Biol. 2005;78:1223-32.

54. Zima T, Kalousov'a M. "Oxidative stress and signal transduction pathways in alcoholic liver disease,". Alcoholism: Clin Exp Res. 2005;29:110S-5S.

55. Sairam K, Rao CV, Dora BM, Agrawal VK, Goel RK. Antiulcerogenic activity of methanolic extract of Emblica officinalis. J Ethnopharmacol. 2002:82:1-9.

56. Kogiannou DAA, Kalogeropoulos N, Kefalas P, Polissiou MG, Kaliora AC. Herbal infusions; their phenolic profile, antioxidant and anti-inflammatory effects in HT29 and PC3 cells. Food Chem Toxicol. 2013;61:152-9.

57. Szabo S. Role of sulfhydryls and early vascular lesions in gastric mucosal injury. Acta Physiol Hung. 1984;64:203-14.

58. Szabo S, Vattay P. Experimental gastric and duodenal ulcers. Advances in pathogenesis. Gastroenterol. Clin. North Am. 1990;19:67-85. 